Research Article

\title{
Extraction and Characterization of Humic Acid from Agriculture Soil and Its Effect on Wheat (Triticum indicum) Seed Growth
}

\author{
Weenghar Ali Chandioํㅜ, Tajnees Pirzada ${ }^{1 *}$, Abdul Majid ${ }^{2}$ and Farzana Rashid ${ }^{3}$ \\ ${ }^{1}$ Institute of Chemistry, Shah Abdul Latif University, Khairpur, Sindh, Pakistan; ${ }^{2}$ Department of Biochemistry, Shah Abdul \\ Latif University, Khairpur, Sindh, Pakistan; ${ }^{3}$ Department of Zoology, Lahore College for Women University, Lahore.
}

\begin{abstract}
The objective of this was to extract and characterize humic acid (HA) from agriculture soil and to investigate its effect on wheat (Triticum indicum) seed growth. HA was conventionally extracted from soil sample of agriculture lands of Khairpur, Sindh, Pakistan by International Humic Substance Society method and confirmed by UV-Visible spectroscopy and characterized by spectral features obtained by using different techniques such as X-ray diffraction (XRD), Fourier transform infrared (FTIR), and scanning electron microscopy (SEM). Finally, the effect of extracted humic acid on wheat seed germination profile including root/shoot length, germination and fresh/ dry weight was investigated by applying varied concentrations of HA $(0,5,10,15$, and 20ppm).UV-Visible spectroscopy confirmed the presence of HA in soil sample. XRD demonstrated that HA extracted had semi-crystalline structure with the average crystal size of $39.48 \times 10^{9} \mathrm{~nm}$. FTIR showed the presence of Oxygen-containing functional groups (aromatic) such as ether bonds, ester bonds, carboxyl group, phenolic hydroxyl group as well as aliphatic hydrocarbon including methyl group, methylene group. SEM exhibited granular structure of HA that were present in aggregates with various shapes and diameter ranging from 5 to $10 \mu \mathrm{m}$. HA with the concentration of $5 \mathrm{ppm}$ showed improved seed germination compared to other concentrations used in this study. This study suggests that HA with the concentration of $5 \mathrm{ppm}$ should be used in agricultural soil for best wheat seed germination. Further research may be conducted for more insight information about mechanism and effects of HA on other plants.

Received | April 29, 2021; Accepted | June 21, 2021; Published | June 30, 2021

*Correspondence | Tajnees Pirzada, Institute of Chemistry, Shah Abdul Latif University, Khairpur, Sindh, Pakistan; Email: tajnees@yahoo.com Citation | Chandio, W.A., T. Pirzada, A. Majid and F. Rashid. 2021. Extraction and characterization of humic acid from agriculture soil and its effect on wheat (Triticum Indicum) seed growth. Journal of Innovative Sciences, 7(1): 199-205.

DOI | https://dx.doi.org/10.17582/journal.jis/2021/7.1.199.205

Keywords | Humic acid, Wheat seeds, agriculture soil, Seed growth
\end{abstract}

\section{Introduction}

$\mathrm{H}$ umic acid (HA) is a group of molecules that bind to plant roots and aid in the absorption of water and nutrients. It is a complex mixture of small, large, and polydisperse molecules that shape and accumulate as a result of microorganism decomposition and transformation (Ding et al., 2019). In the beginning,
Schulten and Schnitzer (1993) suggested HA structure that consisted of alkyl benzene moieties that were covalently bound. (Schulten and Schnitzer, 1993). HA has been reported to be a self-structure of small heterogeneous molecules connected with each other through hydrogen bonds and hydrophobic dispersive forces. Some researchers believe that HA does not possess distinct structures; however, its structure 
dependents upon the source and the exact extraction conditions that produced it (de Souza and Braganca, 2018).It is thought to be a self-assembled superstructure kept together especially by hydrophobic dispersive forces and hydrogen bonds between relatively small heterogeneous molecules. Carboxylic acid, phenolic hydroxyl, sulfonic acid, carbonyl, and methoxy groups are only a few of the active groups found in HA. Acidity, ion exchange, colloidal properties, and complexation properties are all influenced by these factors (Yuan et al., 2018). HA is commonly used in agriculture, medicine, health, and wastewater management (Santos et al., 2016). HA possess negative charge in aqueous solutions due to having carboxylic and phenolic groups (El-sayed et al., 2019).

HA can effectively remove metal ions from water and increase its consistency (do Nascimento and Masini, 2014). In addition, HA channels are used as battery cathode expansion agent, surfactants, water soluble fertilizers, flocculants, soil remediation agent, ceramic additives, boiler anticrustator, and compound fertilizers (Shui-hua et al., 2012). High surface functionality guarantees that $\mathrm{HA}$ is a strong adsorbent with a high ability to manage emissions related to waste gas (Sun et al., 2015). HA is found in lakes, marshlands, lignite, oxidized bituminous rock, weathered coal, shale, and flora/fauna residue (Vaz et al., 2015; Manzak et al., 2017). As a reserve of HA of almost $45 \%$ of global coal reserves and lignite has drawn significant attention (Zhang et al., 2018). However, its direct and widespread use is limited due to the abundance of low calories, high moisture, and oxygen functional moieties (Wang et al., 2018). In comparison to HAs derived from soil and peat, lignite HAs had lower oxygen and nitrogen content, less carboxylic groups, higher carbon content and biochemical activity and more aromatic moieties. Unlike soil HAs, lignite HAs have been found to have saturated long chain alkanoic acids with a clear preference for even numbered homologues (Doskocil et al., 2018).

HA has beneficial effects on plant nutrient uptake, transport and micronutrient availability. In relation to this, one study suggests that high levels of HA negatively effect on the plant growth and decrease the nutrients contents (Turkmen et al., 2004). However, there is insufficient knowledge on the effect of HA on plant growth. Therefore, this study aimed to extract and characterize humic acid (HA) from agriculture soil and to investigate its effect on wheat (Triticum indicum) seed germination.

\section{Materials and Methods}

\subsection{Extraction of humic acid from soil}

For the isolation and purification of HA from agriculture land of Khairpur, Sindh, Pakistan, the International Humic Substances Society (IHSS) method was applied (Zou et al., 2021). $100 \mathrm{~g}$ of dried soil samples were washed with $10 \% \mathrm{HCl}$ and stirred for 1-2 hours at room temperature for decalcination, and then allowed to dissolve in $0.1 \mathrm{M} \mathrm{NaOH}$ at $\mathrm{pH}$ 12 with a sample/extractant ratio of 1:10 and shaken in a mechanical shaker for 7-8 hours. The suspension was centrifuged at low speed (1500 rpm) for 10 minutes, then kept at room temperature overnight to separate the residues from the alkaline solution. After decantation of the supernatant solution, dark brown HA solutions were obtained. It was acidified with concentrated $\mathrm{HCI}(6 \mathrm{M})$ at $\mathrm{pH} 1$ and permitted to stand for 16 hours with continuous stirring. The suspension was centrifuged for 20 minutes at 5000 $\mathrm{rpm}$, keeping the temperature at $4^{\circ} \mathrm{C}$. To isolate the coagulated HA, the supernatant and floating content were discarded, and the HA was thoroughly washed several times with purified water for decalcination. Finally, a sample of HA was collected (Shimadzu) (Xavier et al., 2012).

\subsection{Characterization of humic acid}

Various techniques were employed to characterize HA isolated from agriculture soil.

\section{$2.3 X$-ray diffraction (XRD)}

Powdered XRD patterns of samples were observed by Diffractometer system (XPERT-PRO). The specification for instrumentation were $\mathrm{Cu}$; voltage/ current, $10 \mathrm{kV} / 50 \mathrm{~mA}$; scan speed, $4^{\circ} / \mathrm{min}, 1.5 \mathrm{~nm}$ wavelength, $2 \Theta$ ranging from 10-80 (Xavier et al., 2012).

\subsection{Fourier transform infrared spectroscopy (FTIR)}

SENSIR was used to record the FTIR spectra of samples. Scans were obtained from 4000-400 cm-1 after the samples $(2 \mathrm{mg}$ ) were powdered in a clean glass pestle and mortar (Moraeset al., 2011; Xavier et al., 2012).

\subsection{Scanning electron microscopy (SEM)}

By gold coating the surface of the samples, SEM 
images of the samples were obtained using a Joel JSM-840 SEM with a $10 \mathrm{kV}$ accelerating voltage. Electricity was used in a sputtering system to make the SEM conductive (Xavier et al., 2012).

\subsection{Effect of HA on wheat seed germination}

Untreated and unprocessed wheat (Triticum indicum) seeds were used to test the effect of HA on wheat seed germination on cellulose filter paper using the Paper Towel Method defined by ISTA in light transparent trays in the presence of light (Zhang et al., 2020).

Wheat seeds were washed in distilled water and then placed in a series of petri dishes with filter paper, 10 seeds per plate at about $1 \mathrm{~cm}$.

Filter papers were previously humidified with distilled water. $2 \mathrm{~mL}$ of HA treatment solution with concentrations ranging from 5 to $20 \mathrm{ppm}$ was distributed evenly on filter paper. Seeds were kept humid as well as seed growth was recorded after interval of 24 hours.

Seeds were mounted vertically on racks in an incubator at a controlled temperature $\left(20-300^{\circ} \mathrm{C}\right)$ with aeration.

Seeds were tracked and re-moistened on a regular basis until germination was complete. After 15 days germinated seedling were harvested and germination, root length (RL), shoot length (SL), root and shoot fresh weight (FW) and dry weight (DW) were recorded (Khan et al., 2012; Ullah et al., 2013). DW was achieved after the drying seedlings in oven at $60^{\circ} \mathrm{C}$ for 48 hours. Three replicates were performed for each test along positive and negative controls (soil and water, respectively). Seeds with roots longer than $5 \mathrm{~mm}$ were considered geminated. The germination percentage in each test was measured by root length with a ruler on filter paper. The $\mathrm{RE}$ and, SG were calculated according to following formulae, respectively.

$$
\begin{aligned}
& R E=\frac{\text { mean root length with test sample }}{\text { mean root length with control }} \times 100 \\
& S G=\frac{\text { seed growth with test sample }}{\text { seed germination with control }} \times 100
\end{aligned}
$$

2.7 Statistical analysis

With the assistance of IBM SPSS Statistics V21.0 relative root elongation ( $\mathrm{RE}$ ) seed germination $(\mathrm{SG})$,

software, data was analyzed using analysis of variance (ANOVA), and then the least significant difference (LSD) test was used to compare the humic acid treatment means.

\section{Results and Discussion}

\subsection{Humic acid extraction from soil}

$\mathrm{UV}-\mathrm{V}$ is is a significant strategy for recognizing the sub-atomic construction of HA. The area and force of the pinnacles are firmly identified with the unsaturated securities and substituent gatherings of the particle. Investigation of the separated HA arrangement was performed by recording the spectra from 200 to 900 $\mathrm{nm}$ is appeared in Figure 3.

The assimilation sign of $\mathrm{HA}$ diminished monotonically in the apparent light locale (400$700 \mathrm{~nm})$. For the close bright locale (200-400nm), a frail retention level (sweet-smelling structure) showed up alongside an enormous ingestion top at cycle $400 \mathrm{~nm}$, demonstrating the presence of formed carbonyl gatherings with two twofold bonds in the HA particle. This outcome was predictable with the aftereffects of the infrared range investigation and demonstrated that HA contained more oxygencontaining utilitarian gatherings which shows that the UV-Vis spectra of secluded humic acids from soil and coal and are comparable in nature (Xavieret al., 2012).

\subsection{Characterization of humic acid ( $H A)$}

\subsubsection{XRD analysis}

The crystalline nature of isolated humic acid were investigated by XRD the pattern exhibited which shown in Figure 1.

In the XRD example of detached humic acid, appearance of blue shading clear sharp force tops at $17.26^{\circ}, 31.85^{\circ}, 44.61^{\circ}$ and $45.59^{\circ}$ which demonstrates the translucent idea of particles present in disengaged humic acid as demonstrated in Figure 1. The red shading force tops which demonstrates the particles in secluded humic acid overall it very well may be reasoned that detached humic acid is semi translucent the normal gem size was $39.48 \times 10-9 \mathrm{~nm}$. DebyeScherer's formula given underneath.

$$
D=k \lambda / \beta \operatorname{Cos} \theta
$$

Where; $k$ is Sherrer steady (1.542A), $\beta$ is the full width

Journal of Innovative Sciences

June 2021 | Volume 7 | Issue 1 | Page 201 
at half-most extreme, $\lambda$ is the $\mathrm{X}$-beam frequency, and $\theta$ is the Bragg diffraction point.

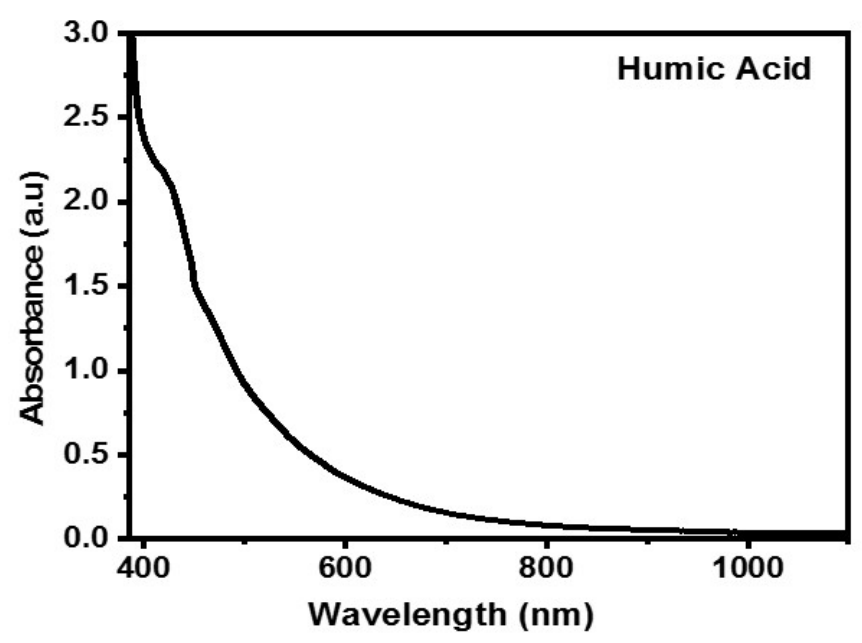

Figure 1: UV-VIS spectra of isolated Humic acid.

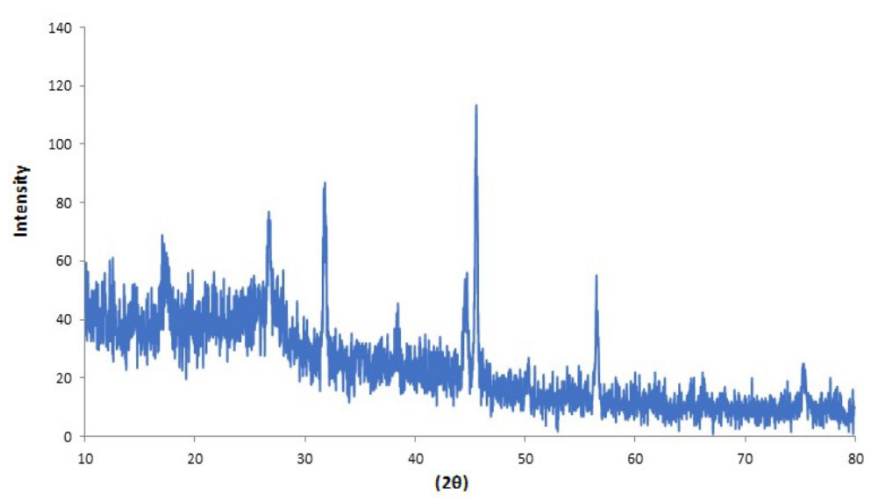

Figure 2: X-ray diffraction pattern of isolated humic acid from soil.

\subsection{Fourier transform infrared spectroscopy (FTIR)}

The varieties in the natural practical gatherings present in the HAs were assessed by FTIR investigation FTIR spectra were recorded in the scope of 4500$400 \mathrm{~cm}^{-1}$ (Figure 3). In the locale of $\sim 3500 \mathrm{~cm}^{-1}$, the hydrogen holding associations structure of free hydroxyl gatherings and $\pi$ bonds usually get weakened. In the 3600 to $3300 \mathrm{~cm}^{-1}$ territory, the HA particles had solid and wide assimilation tops. These pinnacles ought to be ascribed to the hydrogen bondrelated - $\mathrm{OH}$ extending or - $\mathrm{NH}$ extending vibration assimilation tops in phenolic and carboxylic corrosive constructions. This outcome showed that the oxygencontaining useful gatherings, for example, ether bonds and ester bonds in separated HA and expanded the substance of carboxyl gatherings and phenolic hydroxyl bunches in HA atoms. The extending vibration retention groups of aliphatic $\mathrm{C}-\mathrm{H}$ bonds were in the 3000 to $2700 \mathrm{~cm}^{-1}$ territory. Among these wavenumbers, $2923 \mathrm{~cm}^{-1}$ and $2853 \mathrm{~cm}^{-1}$ were the even and lopsided extending vibrational pinnacles of the $\mathrm{C}-\mathrm{H}$ securities in the immersed hydrocarbon gatherings $-\mathrm{CH}_{3}$ and $-\mathrm{CH}_{2}$, individually.
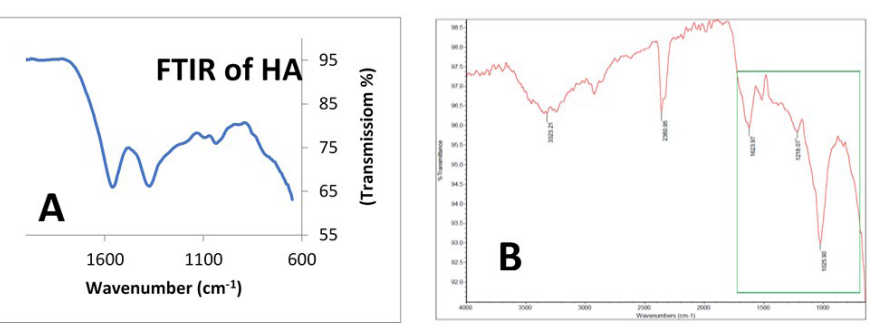

Figure 3: FTIR spectra of isolated humic acid (A, B).

Inside this reach, the force of the assimilation pinnacle of $\mathrm{CH}_{3}$ at $2923 \mathrm{~cm}^{-1}$ for HA. Be that as it may, the tops in the 1900 to $1000 \mathrm{~cm}^{-1}$ territory were predominantly credited to the oxygen-containing useful gatherings in $\mathrm{HA}$. The top at $1696 \mathrm{~cm}^{-1}$ addressed the sharp $\mathrm{C}=\mathrm{O}$ extending vibration pinnacle of carboxylic acids, aldehydes, and ketones. The top at $1604 \mathrm{~cm}^{-1}$ might be ascribed to $\mathrm{C}=\mathrm{O}$ in amides (amide I band), quinones, or ketones. The tops in the expansive recurrence scope of 1550 to $1790 \mathrm{~cm}^{-1}$ could be essentially credited to protonated carboxylic corrosive $(-\mathrm{COOH})$, carboxylate anion (- COO-), and ester carbonyl (- COOR) gatherings, just as to some other utilitarian gatherings. The top at $1440 \mathrm{~cm}^{-1}$ was allotted as the out-of-plane extending vibrational retention pinnacle of $\mathrm{C}-\mathrm{H}$ in aliphatic $\mathrm{CH}_{3}$. The top at $1371 \mathrm{~cm}^{-1}$ was ascribed to the twisting of the hydroxyl bunch, the $\mathrm{C}-\mathrm{O}$ extending vibration of a phenolic hydroxyl bunch, the $\mathrm{C}-\mathrm{H}$ disfigurement of a methyl or methylene bunch, or the topsy-turvy extending vibration of $\mathrm{COO}^{-}$.

\subsection{Scanning electron microscopy (SEM) analysis}

The morphology of HA was examined utilizing SEM. SEM showed the granular design of HA that have been removed from soil sources (Figure 4). By and large, they show semi gem like structures total alongside different shapes. The precious stones have been found in XRD examination with breadths in the scope of 5 to $10 \mu \mathrm{m}$ (Figure $4 \mathrm{~A}, \mathrm{~B}$ ). This outcome is in concurrence with other examination (Xavieret al., 2012).

\subsection{Effect of HA on wheat seed growth}

\subsubsection{Percent germination in the hydroponic culture}

It is obvious from the data (Figure 5) that wheat seeds have germinated in HA. However, HA with the concentration of $5 \mathrm{ppm}$ showed improved seed growth compared to other concentrations used in this 
study $(p>0.05)$. The findings of this research were consistent with those of other studies which reported that higher HA negatively effect on seed growth (Türkmen et al., 2004).
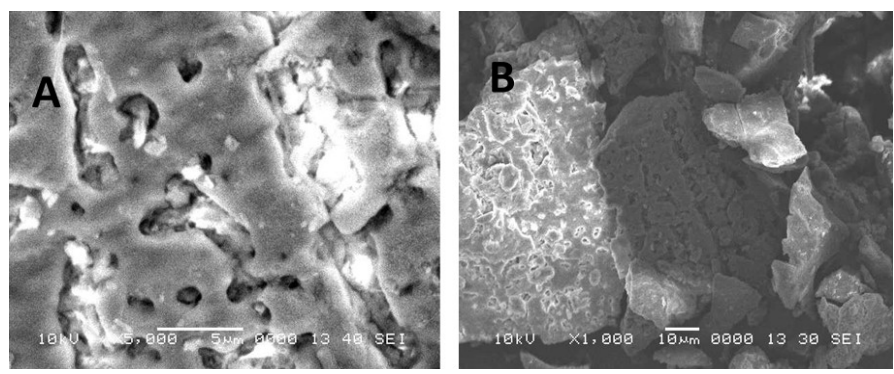

Figure 4: SEM images of isolated Humic acid, (A) $5 \mu \mathrm{m}$, (B) $10 \mu \mathrm{m}$.

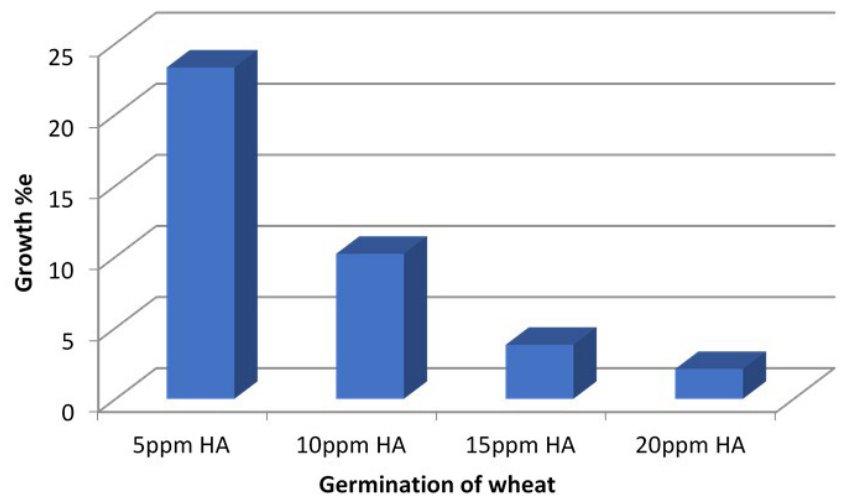

Figure 5: Effect of different concentrations of HA on seed germination of wheat.

\subsubsection{Plant height in the bydroponic culture (Shoot length)}

The shoot length of wheat seedlings in HA was measured from 0 to $20 \mathrm{ppm}$. at different concentrations of synthetic fertilizer HA, the shoot length effect of wheat plant was estimated with $\mathrm{HA}$, at $5 \mathrm{ppm}$ $(37.13 \mathrm{~mm}), 10 \mathrm{ppm}(17.2 \mathrm{~mm}) 15 \mathrm{ppm} \quad(11.7 \mathrm{~mm})$ $20 \mathrm{ppm}(9.7 \mathrm{~mm})$ but foliar application of HA affected plant growth, especially in a lowheight concentration (Figure 6). These results are in consistent with other study (E1-Ghamry et al., 2009).

\subsubsection{Plant height in the hydroponic culture (Root length)}

The effect of synthetic fertilizer HA concentrations on the root length of wheat variety are shown in Figure 7. The root length of wheat species in HA ranged from 0 to $20 \mathrm{ppm}$. Root length of wheat plant for effect of HA, were as follows: At $5 \mathrm{ppm}(18.1 \mathrm{~mm}) 10 \mathrm{ppm}$ $(16.42 \mathrm{~mm}) 15 \mathrm{ppm}(14.89 \mathrm{~mm}) 20 \mathrm{ppm}(13.9 \mathrm{~mm})$. The root length was found to be inhibited when the HA concentration was increased. At $5 \mathrm{ppm}$, there was a significant increase in root length $(\mathrm{P}>0.05)$.

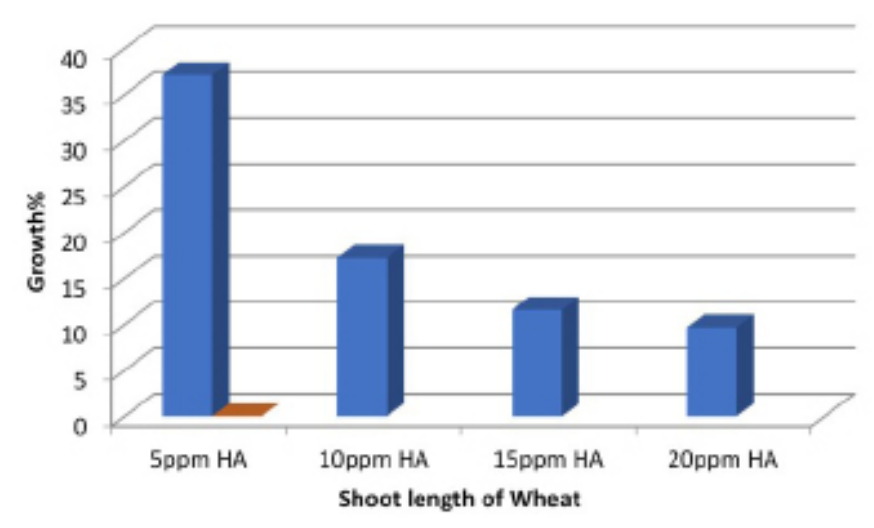

Figure 6: Effect of different concentration of HA on shoot length of wheat.

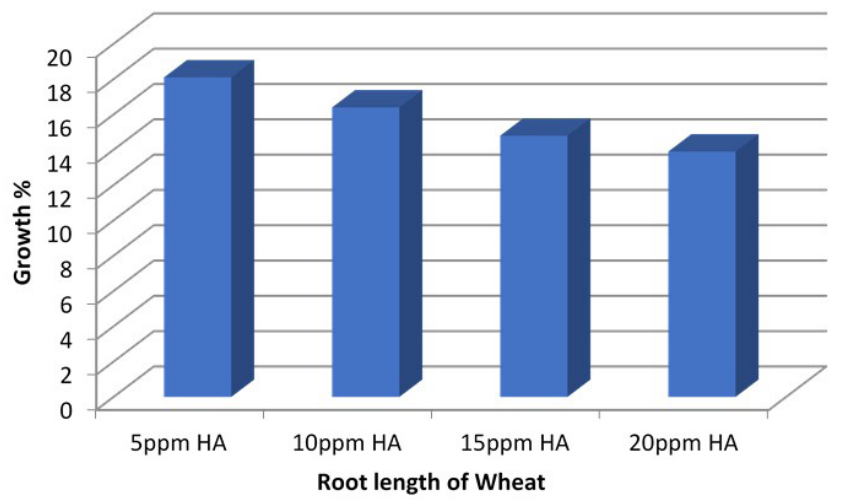

Figure 7: Effect of different concentration of HA on root length of wheat.

\subsection{Effect of $H A$ on growth parameters (fresh and dry} weight of wheat seeds)

Figure 8 shows the effect of synthesized fertilizer (HA) on the fresh/dry weight of wheat species. also see Figure 9. By affecting their fresh/dryweights at distinct concentrations, the application of synthetic fertilizers significantly affected wheat seeds. The treatments had no noticeable effect on the weight of the fresh/ dry plants. Data relating to the synthetic effect shows the effect of synthesized fertilizer (HA) on the fresh/ dry weight of wheat species. The fresh/dry weights of synthetic fertilizers at various concentrations had a significant impact on their application. The effects of synthetic fertilizer treatment, HA with all treatments $5,10,15,20 \mathrm{ppm}$ on fresh/dry weight of shoot and root of wheat species are shown in Figures 8 and 9. The fresh/dry weight of wheat shoots and roots in HA ranged from 0 to $20 \mathrm{ppm}$. Fresh/dry weight of wheat at $5 \mathrm{ppm}(1.23 / 0.57 \mathrm{~g}) 10 \mathrm{ppm}(1.13 / 0.37 \mathrm{~g})$, $15 \mathrm{ppm}(1 / 0.23 \mathrm{~g})$, and $20 \mathrm{ppm}(0.93 / 0.20 \mathrm{~g})$. The data show that increasing the HA concentration to $20 \mathrm{ppm}$ significantly decreased the fresh/dry weight of the shoot and root $(\mathrm{P}>0.05)$. 


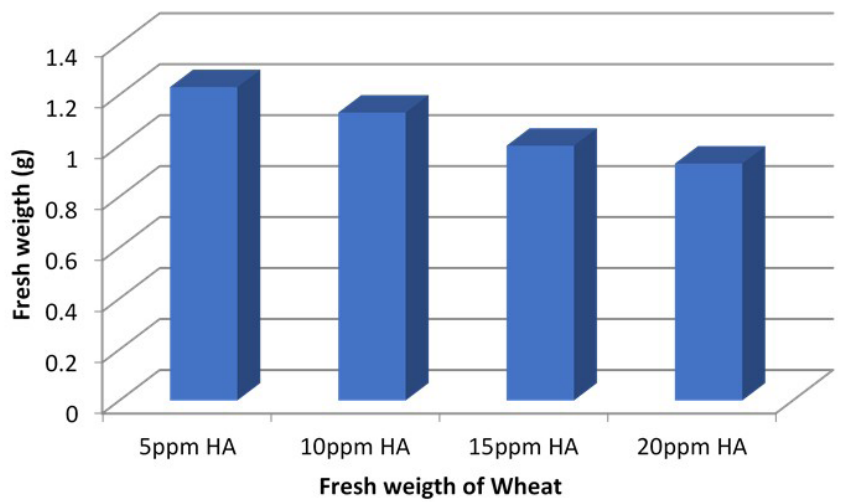

Figure 8: Effect of different concentration of $\mathrm{HA}$ on fresh weight of wheat.

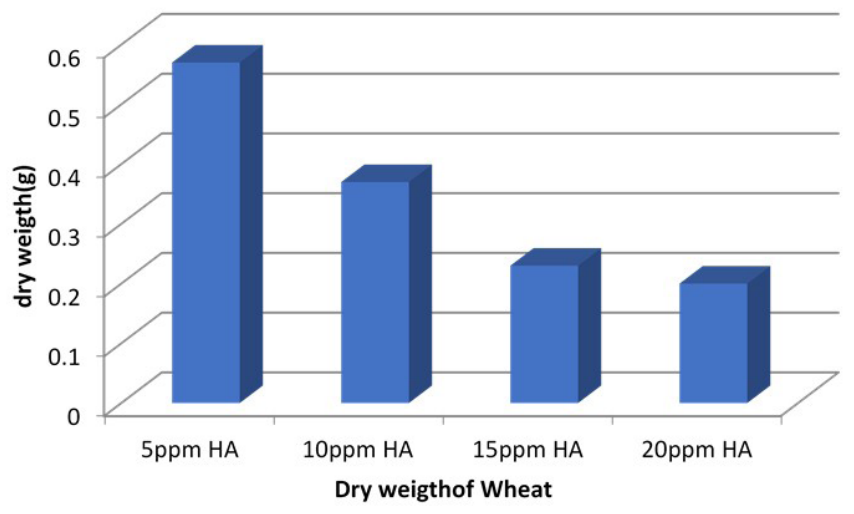

Figure 9: Effect of different concentration of HA on dry weight of wheat.

\section{Conclusions and Recommendations}

The soil humic acid investigated in this study was conventionally isolated from agriculture lands of Khairpur Sindh by IHSS method and spectral features obtained by using various techniques such as $\mathrm{X}$-ray diffraction, Fourier transform infrared (FTIR), scanning electron microscopy (SEM) and UV-Vis spectroscopy. The results show that carboxylic and phenolic groups are abundant in isolated HA, which contribute the most to humic material surface charge and reactivity. This study indicated that humic acid with the concentration of $5 \mathrm{ppm}$ should be used in agricultural soil for best wheat seed growth. Further research may be conducted for more insight information about mechanism and effects of HA on other plants.

\section{Acknowledgements}

The first author acknowledges Institute of Chemistry, Shah Abdul Latif University, Khairpur, Sindh
Pakistan for providing laboratory facilities to perform experimental work.

\section{Novelty Statement}

Humic acid for wheat germination has not been reported so far as per available literature.

\section{Author's Contributions}

TP: Conception and design.

WAC: Collection and assembly of data.

WAC: Analysis and interpretation of the data.

WAC, TP, MMAT, AM, SL: Drafting of the article. TP, AM: Critical revision of the article for important intellectual content.

AM: Statistical expertise.

TP, AM: Revision of article.

TP: Final approval and guarantor of the article.

\section{Conflict of interest}

The authors declared no conflict of interest.

\section{Ethical approval}

Not applicable

\section{References}

de Souza, F. and Bragança, S.R., 2018. Extraction and characterization of humic acid from coal for the application as dispersant of ceramic powders. J. Mater. Res., 7(3): 260. https://doi. org/10.1016/j.jmrt.2017.08.008

Ding, Y., Liu, M., Peng, S., Li, J., Liang, Y. and Shi, Z.2019. Binding characteristics of heavy metals to humic acid before and after fractionation by ferrihydrite. Chemosphere, 226: 140-148. https:// doi.org/10.1016/j.chemosphere.2019.03.124

do Nascimento, F.H. and Masini, J.C. 2014. Influence of humic acid on adsorption of $\mathrm{Hg}$ (II) by vermiculite. J. Environ. Manag., 143: $\quad$ 1-7. $\quad$ https://doi.org/10.1016/j. jenvman.2014.04.013

Doskočil, L., Burdíková-Szewieczková, J., Enev, V., Kalina, L. and Wasserbauer, J. 2018. Spectral characterization and comparison of humic acids isolated from some European lignites. Fuel, 213: 123-132. https://doi.org/10.1016/j. fuel.2017.10.114

El-Ghamry, A.M., Abd El-Hai, K.M. and Ghoneem, K.M., 2009. Amino and humic acids 
promote growth, yield and disease resistance of faba bean cultivated in clayey soil. Aust. J. Basic Appl. Sci., 3(2): 731-739.

El-sayed,M.E., Khalaf,M.M., Gibson, D. and Rice, J.A.,2019.Assessment of clay mineral selectivity for adsorption of aliphatic/aromatic humic acid fraction. Chem. Geol., 511: 21-27. https://doi. org/10.1016/j.chemgeo.2019.02.034

Khan, N., Naveed, K., Hussain, Z. and Alam Khan, S., 2012. Assessment of allelopathic effects of parthenium (Parthenium hysterophorus L.) plant parts on seed growth and seedling growth of wheat (Triticum aestivum L.) cultivars. Pak. J. Weed Sci. Res., 18(1): 39-50.

Manzak, A., Kurşun, C. and Y1ldız, Y., 2017. Characterization of humic acid extracted from aqueous solutions with polymer inclusion membranes. J. Taiwan Inst. Chem. Eng., 81: 1420. https://doi.org/10.1016/j.jtice.2017.10.024

Moraes, G.M.D., Xavier, F.A.D.S., Mendonça, E.D.S., Araújo Filho, J.A.D. and Oliveira, T.S.D., 2011. Chemical and structural characterization of soil humic substances under agroforestry and conventional systems. Rev. Bras. Cienc. Solo., 35(5): 1597-1608. https://doi. org/10.1590/S0100-06832011000500014

Piccolo, A., 2001. The supramolecular structure of humic substances. Soil science, 166(11): 810-832. https://doi.org/10.1097/00010694200111000-00007

Santos, A., Rodríguez, S., Pardo, F. and Romero, A., 2016. Use of Fenton reagent combined with humic acids for the removal of PFOA from contaminated water. Sci. Total Environ., 563: 657-663. https://doi.org/10.1016/j. scitotenv.2015.09.044

Schulten, H.R. and Schnitzer, M., 1993. A state of the art structural concept for humic substances. Naturwissenschaften, 80(1): 29-30. https://doi. org/10.1007/BF01139754

Shui-hua, Z.H.A.N.G., Baocai, L.I. and Huifen, Z.H.A.N.G., 2012. Experimental study on the production of humic acids from brown coal using hydrogen peroxide. J. Anhui Agric. Univ., 40(15): 8677-8679.

Sun, Z., Tang, B. and Xie, H., 2015. Treatment of waste gases by humic acid. Energy and Fuels, 29(3): 1269-1278. https://doi.org/10.1021/ ef502299k
Türkmen, Ö., Dursun, A., Turan, M. and Erdinç, Ç., 2004. Calcium and humic acid affect seed growth, growth, and nutrient content of tomato (Lycopersicon esculentum L.) seedlings under saline soil conditions. Acta Agr. Scand. B-S P. 54(3): 168-174. https://doi. org/10.1080/09064710310022014

Ullah, A., Khan, E.A., Baloch, M.S., Nadim, M.A., Sadiq, M. and Noor, K., 2013. Allelopathic effects of herbaceous and woody plant species on seed growth and seedling growth of wheat. Pak. J. Weed Sci. Res., 19(3): 357-375.

Vaz Jr, S., Lopes, W.T. and Martin-Neto, L., 2015. Study of molecular interactions between humic acid from Brazilian soil and the antibiotic oxytetracycline. Environ. Technol., 4: 260-267. https://doi.org/10.1016/j.eti.2015.09.004

Wang, C., Xiao, Y., Li, Q., Deng, J. and Wang, K., 2018. Free radicals, apparent activation energy, and functional groups during low-temperature oxidation of Jurassic coal in Northern Shaanxi. Int.J. Min. Sci. Techno., 28(3): 469-475. https:// doi.org/10.1016/j.ijmst.2018.04.007

Xavier, D.M., Silva, A.S., Santos, R.P., Mesko, M.F., Costa, S.N., Freire, V.N., Cavada, B.S. and Martins, J.L. 2012. Characterization of the coal humic acids from the candiota coalfield, Brazil. Int. J. Agric. Sci., 4(5): 238. https://doi. org/10.9735/0975-3710.4.5.238-242

Yuan, D., Xie, L., Shi, X., Yi, L., Zhang, G., Zhang, H., Liu, Q. and Zeng, H., 2018. Selective flotation separation of molybdenite and talc by humic substances. Miner. Eng., 117: 34-41. https://doi.org/10.1016/j.mineng.2017.12.005

Zhang, K., Wang, Y., Mao, J. and Chen, B., 2020. Effects of biochar nanoparticles on seed germination and seedling growth. Environ. Pollut., 256: 113409. https://doi.org/10.1016/j. envpol.2019.113409

Zhang, Y.Y., Zong, Z.M., Sun, Y.B., Liu, F.J., Li, W.T., Wang, Y.N. and Wei, X.Y., 2018. Investigation on the structural feature of Shengli lignite. Int. J. Min. Sci. Technol., 28(2): 335-342. https://doi.org/10.1016/j.ijmst.2017.05.022

Zou, J., Zhang, H., Yue, D. and Huang , J. 2021. Is the traditionally alkali extraction method in isolating chemically distinct humic acid?. Chem. Eng.J. Adv., 6:100077. 